\title{
Wellbore Stability Problems in Deepwater Gas Wells
}

\author{
Azeez G. Aregbe \\ Oil and Gas Well Engineering, China University of Petroleum (East China), Qingdao, China \\ Email: aregbeazeez@yahoo.com, aaregbe@unilag.edu.ng
}

How to cite this paper: Aregbe, A.G. (2017) Wellbore Stability Problems in Deepwater Gas Wells. World Journal of Engineering and Technology, 5, 626-647. https://doi.org/10.4236/wjet.2017.54053

Received: August 29, 2017

Accepted: October 24, 2017

Published: October 30, 2017

Copyright $\odot 2017$ by author and Scientific Research Publishing Inc. This work is licensed under the Creative Commons Attribution International License (CC BY 4.0).

http://creativecommons.org/licenses/by/4.0/

\begin{abstract}
The analysis of wellbore stability in deepwater gas wells is vital for effective drilling operations, especially in deepwater remote areas and for modern drilling technologies. Wellbore stability problems usually occur when drilling through hydrocarbon formations such as shale, unconsolidated sandstone, fractured carbonate formations and HPHT formations with narrow safety mud window. These problems can significantly affect drilling time, costs and the whole drilling operations. In deepwater gas wells, there is also the possible of gas hydrate problems because of the low temperature and high pressure conditions of the environment as well as the coexistence of gas and water inside the wellbore. These hydrates can block the mud line, surface choke line and even the BOP stack if no hydrate preventive measures are considered. In addition, the dissociation of these hydrates in the wellbore may gasify the drilling fluid and reduce drilling mud density, hydrostatic pressure, change mud rheology and cause wellbore instabilities. Traditional wellbore stability analysis considered the formation to be isotropic and assumed that the rock mechanical properties are independent of in-situ stress direction. This assumption is invalid for formations with layers or natural fractures because the presence of these geological features will influence rock anisotropic properties, wellbore stress concentration and failure behavior. This is a complicated phenomenon because the stress distribution around a wellbore is affected by factors such as rock properties, far-field principal stresses, wellbore trajectory, formation pore pressure, reservoir and drilling fluids properties and time. This research work reviews the major causes of wellbore stability problems in deepwater gas wells and outlines different preventive measures for effective drilling operation, because real-time monitoring of drilling process can provide necessary information for solving any wellbore stability problems in a short time.
\end{abstract}

\section{Keywords}

Wellbore Instability, Hydrate-Related Problems, Deepwater Gas Wells, Shale, Fractures, Faults 


\section{Introduction}

Deepwater exploration is a difficult and highly risky operation due to problems such as wellbore instability that occur while drilling. There have been remarkable accomplishments in the development of technologies that allow drilling deepwater wells to access more resources. The deepwater wellbore design is not entirely different from the normal onshore drilling process used for onshore drilling. The major discrepancies are the rig types and methods used in executing the operations. For deepwater drilling, platforms/floating vessels are required for the deepwater operations. More than $70 \%$ of all drilled formations (offshore \& onshore) are shale formations and about $90 \%$ of wellbore stability problems occurred in these shale formations [1]. Shale formations with enormous organic matters are not the same with the conventional formations due to the characteristic of the source rocks, such as rich organic matter and developed fracture networks. Wellbore instability is a major problem encountered in deep water shale gas wells. The wellbore quality plays a fundamental role in drilling operations as well as in well completion which translate to effective oil and gas production. Most formations especially shale formations drilled with oil-based drilling fluids perform better than those drilled with water-based fluids but some researchers have reported that oil-based drilling fluids are not the best solution to the problems that occur while drilling shale gas wells and different alternatives have been proposed.

Wellbore instability can also be caused by the formation and dissociation of hydrates which are ice-like crystalline compounds formed when gas and water molecules coexist at low temperature and high pressure. Most of the deepwater gas wells will encounter gas hydrate problems because of the low temperature and high-pressure conditions of the deep-water environments [2].

The required water for hydrate formation comes from either drilling fluid or formation water produced with the influx of gas. The required water can also come from condensed water from natural gas and water/gas-water transition zones. There are series of reported hydrate-related wellbore stability problems such as gas influx, wellbore collapse, stuck pipe, etc. The dissociation of gas hydrate in the wellbore can gasify the drilling fluid, reduce drilling mud density, change mud rheology and decrease hydrostatic pressure in the wellbore.

Wellbore instability problems during drilling have also been reported in naturally fractured formations [3]. Most of the reported formations have macro and micro scale bedding planes and networks of natural fractures that affect the strength and the producibility of the matrices in the formation. Despite the challenges with complexity, development of improved drilling technology has enhanced drilling more complex well designs to a greater depth for exploring more hydrocarbon reserves. This has created rooms for wells to be developed at a greater distance from the drilling or production structure to access more reserves with less environmental impacts. A reliable wellbore stability analysis depends on good understanding of the properties of the deepwater formation to be 
drilled. It is anticipated that advanced drilling technologies will be developed in the nearest future to ensure improved drilling performance which ultimately prevents wellbore stability problems in deepwater gas well drilling and reduce environmental impact. Due to increase in deepwater gas well drilling, the potential for hydrate wellbore stability problems during drilling has increased in recent years. And continuous understanding and elaborate research on hydrate-related drilling problems will certainly enhance the production of the enormous resource in these gas hydrate formations [2] [3] [4].

\section{Literature Review/Theoretical Principles}

Innovations and technological development in deepwater drilling widely began in recent years when shallow water depth platforms were utilized to access deepwater reservoirs. There has been significant hydrocarbon production from deepwater reserves and different challenges such as wellbore instability have also been encountered while exploring and developing these reserves. Some of the research works conducted on these challenges are:

Asadi et al., [5] worked on Wellbore Stability Analysis in Depleted Deepwater Reservoirs: A Case Study from Australia. The principal minimum horizontal stress was calibrated against extended leak-off tests, micro-frac and injectivity tests in 12 offset wells using log-based poroelastic and effective stress ratio methodologies. They also constrained and calibrated the geomechanical model with the use of a range of well logs, drilling data and core experiments. They used the model to compute the fracture initial pressure and its variation with borehole trajectory for a number of horizontal wells under the initial and depleted conditions. Their results showed that for the well trajectories, the mud weight window is extremely narrow if the formation fracture gradient is equivalent to the fracture initial pressure.

Klimentos, [6] researched on a paper presentation titled "Optimizing Drilling Performance by Wellbore Stability and Pore Pressure in Deepwater Exploration". The paper reported the major drilling problems related to wellbore instability and pore pressure in deepwater wells. There was a case study from a deepwater well with the history of wellbore stability and loss circulation problems. The details of the report included properties i.e. mud weight as a function of deviation angle, rock strength and computed pore pressure. Rock strength determination with the optimum mud weight windows were reported to improve the overall drilling performance in the next deep water well by minimizing wellbore stability problems. Improvement in bit performance was also achieved by using the predicted values of the rock compressive strength.

Wellbore Stability Evaluation of Mishrif Formation in southern Iraq was studied by Alkamil et al., [7]. They reported that stuck pipe was identified as a major geomechanical problem in several wells. In their study, a 1-D mechanical earth model (MEM) of the Mishrif formation was compiled based on the stress on and the rock strength parameters of the formation. The mechanical earth 
model was used to assess the influence of borehole collapse and subsequent stuck pipe problems. The MEM model was based on the principles of in-situ stresses and their orientations measured from Wireline logs measurements, measurement while drilling and leak-off tests. The results of their work showed that wells characterized by stuck pipe were drilled along azimuths which enhanced wellbore collapse. They also computed mud pressure window and suggested stable azimuths and inclinations for each well in the formation.

Van Oort et al., [8] researched on Silicate-Based Drilling Fluids: Competent, Cost effective and Benign Solutions to Wellbore Stability Problems. They developed and applied new water-based drilling muds by using soluble silicates in the field. Silicate based muds were introduced as superior fluids for drilling troublesome formations like intact and fractured shale and chalk rocks. The inorganic drilling fluid systems developed are environmentally friendly and inexpensive. They also presented detailed reports on the wellbore stabilization mechanism of silicate-based muds and their drilling fluid engineering. They conducted and reported field trial results which demonstrate the excellent cuttings and wellbore stabilizing capacity of their newly developed drilling fluid systems.

A case study on the analysis of wellbore stability in multilateral well design and construction was conducted by Anyanwu et al., [9]. They studied wellbore stability with an emphasis on multilateral wells and developed a modified failure model by using a stress concentration factor based on the junction configurations. The Mogi criterion was used to account for intermediate stress and predicted the minimum mud pressure for shear failure. A risk and uncertainty factor was also computed for sensitive model parameters such as stress concentration factors, and lateral bore entry angle. They compiled the results from two case studies and showed that collapse gradient prediction by Mogi based model was more reliable than those of Mohr based model.

Willson et al., [10] wrote an SPE article on Wellbore-Stability Challenges in the Deepwater Gulf of Mexico: Case History Examples from the Pompano Field. They also discussed the problems of drilling depleted sands, wellbore instability at high angles, and the hazards associated with drilling subsalt extended-reach wells. They concluded by giving recommendations for preplanning activities, drilling practices, and real-time wellbore stability management for effective operation on the field.

Fekete et al., [11] researched on the Wellbore Stability Management in Weak Bedding Planes and Angle of Attack in Well Planning. They outlined the effect of shale bedding plane failure on wellbore stability and the possible angle of attack for stabled rilling operations in weak bedding planes. They developed a robust tool to account for the conditions needed to identify and drill through weak bedding planes, the rock compressive strength for weak bedding planes, minimum mud pressure to prevent shear failure and wellbore slip as well as suitable attack angle. Their proposed tool was able to increase drilling efficiency and was validated with field data. The new rock strength for weak bedding planes was 
used to predict minimum mud pressure required for preventing shear failure and wellbore slip shear failure in weak bedding planes.

Van den Hoek et al., [12] conducted an experimental work on Horizontal-Wellbore Stability and Sand Production in Weakly Consolidated Sandstones. They studied the effects of rock failure in the near-wellbore region on well productivity. They prepared blocks of weak artificial sandstone and holes were drilled in these blocks. The production conditions at different in-situ stress, drawdown and water cut, with and without liners were also simulated. Their experimental results showed that in the presence of a slotted liner and absence of water cut, rock failure caused gradual annulus fill-up with looses and. They concluded that rock failure around uncemented liner completions will not be noticed at the wellhead and also stated that the introduction of a small $(<5 \%)$ water cut will result in massive sand production and subsequent collapse of the liner because water cut destroys capillary cohesion, thus destabilizing sand arches over the slots.

Wellbore instability is an undesirable condition in which the gauge size, shape and structural integrity of an open hole section of a wellbore are altered. Wellbore instabilities are causes by mechanical failure due to alteration in the in-situ stresses, erosion due to fluid circulation, and chemical interaction between the drilling fluid and formation fluids/minerals. Wellbore instabilities in deepwater gas wells are divided into four categories which are:

1) Wellbore closure

This is a narrowing time-dependent process which is often called creep under the effect of overburden pressure. Wellbore closure is common in shale and salt formations. When there are stresses at the wellbore wall, this will create a decrease in the size of the wellbore. This can lead to the closure of uncased wellbore sections. The drilling problems associated with borehole closure are increase in torque and drag, stuck pipe and problems with casings landing.

2) Wellbore enlargements

This is also known as washout because the wellbore size becomes undesirably larger than the original size. This can occur as a result of erosion, abrasion, and shale sloughing. This creates difficulty in cementing operation, potential wellbore deviation, affects hydraulic requirements and causes problems during logging operations.

3) Fracturing

Fracturing occurs when the mud column hydrostatic pressure is relatively more than the formation fracture pressure. The positive pressure difference is exerted on the wellbore wall and subsequently, fractures the formation. This will lead to lost circulation of drilling fluid into the formation and possible influx of formation fluids into the wellbore. If there is influx of gas in a deepwater gas well with low temperature and high pressure, gas hydrate can be formed. The gas hydrate formed will block the choke/kill line, riser, ram cavity and even the BOP stack. This can affect well control operation and wellbore integrity. 
4) Wellbore collapse

Wellbore collapse occurs when the drilling mud hydrostatic pressure is too low to support the integrity of the wellbore. This can also create formation influx and lead to blowout if not properly controlled. It can lead to stuck pipe and possible loss of well.

\subsection{Causes of Wellbore Instability}

Wellbore instability in deepwater gas well is influenced by different factors such as drilling mud chemistry and reservoir properties. Drilling fluid properties can be used to influence wellbore stability directly. The properties of drilling fluids that can be optimized to influence wellbore stability are filtration behavior, physicochemical interaction with the formation and the mud density [13]. The low temperature, high pressure and low gas density in deepwater environments make the formation of hydrates possible. These hydrates are mostly formed at low temperature, high pressure and low gas production rate, under well testing conditions. Hydrate formation and dissociation can affect the properties of drilling fluid and cause wellbore collapse or formation damage [2] [14]. Wellbore instability problems during drilling have also been reported in naturally fractured formations. Most of the reported formations have macro and micro scale bedding planes and networks of natural fractures that weakens the compressive strength of the formation and the producibility of the matrices in the formation [15]. The natural fractures in the formation change the wellbore stress and reduce the fracture resistance of the formation.

\subsubsection{Shale Instability}

Most deepwater gas formations are shale formations and are the major cause of wellbore instability problems. Shale formations are fine-grained sedimentary rocks composed of mainly clay, silts, and sometimes, sand particles. Shale formations range from clay-rich, weak formations to shaly siltstone, highly cemented formations [16]. They have extremely low permeability and high proportion of clay minerals. Over $75 \%$ of drilled deepwater formations are shale formations and drilling cost attributed to shale instability problems is extremely high. The causes of shale instability are mechanical instability and chemically induced instability as a result of interaction between mineral compositions of the formation and drilling fluid [17].

When drilling fluid and shale minerals interact, the mechanical strength and pore pressure of the formation in the vicinity of the wellbore are altered. The factors that contribute to this wellbore problem are capillary pressure, osmotic pressure, pressure diffusion in the vicinity of the wellbore and wellbore fluid invasion during overbalanced drilling [17] [18]. During drilling, the drilling mud in the wellbore contacts the formation fluid through the pore-throat interface and as a result, capillary pressure is formed. Capillary pressure, $P_{c}$, can be expressed as, Equation (1). 


$$
P_{c}=\frac{2 \sigma_{m f} * \cos \theta_{m f}}{r}
$$

where $\sigma_{m f}$ is the interfacial tension, $\theta_{m f}$ is the contact angle between the drilling mud and formation fluid, and $r$ is the radius of the pore-throat. In order to prevent wellbore fluids from entering the formation, an increase in capillary pressure is required. This can be achieved with oil-based or other organic low-polar drilling mud systems. If the energy level of the formation fluid is different from that in drilling fluid, water movement through a semi-permeable membrane in either direction occur due to the osmotic pressure or chemical potential. This can be prevented or minimized by ensuring that the energy levels are close to each other. This can be achieved by using additives such as saturated salt, polymer, and lime/gypsum.

In normal drilling operation, a positive pressure differential is usually maintained. This causes drilling fluid to flow into the formation (loss circulation) and chemically interact with the minerals in the formation leading to shale instabilities. In order to prevent this problem, an increase of drilling fluid viscosity or special material such as Gilsonite can be used to seal off micro fractures in the formation. Drilling with a positive pressure differential through a shale formation with water-based drilling mud, will allow drilling fluid pressure to penetrate the formation. Because of the saturation and low permeability of the formation, the penetration of drilling mud filtrate into the formation will increase formation pore pressure around the wellbore wall. This increase in formation pore pressure will reduce the effective drilling mud pressure and can lead to wellbore instability. Several polymer water-based drilling fluid systems have been developed to prevent shale hydration and are being used in place of oil-based drilling fluids and synthetic-based fluids [18] [19].

\subsubsection{Mechanical Instability}

Mechanical instability usually occurs when the in-situ stresses of the formation is disturbed after drilling. In order to analyze the stability of deepwater gas wells, it is important to define the initial in-situ conditions of the formation. The first step in this analysis is to determine the formation pore pressure, rock compressive strength and stresses acting on the formation at the wellbore wall [16] [17] [18]. There are three in-situ principal stresses (one vertical and two horizontal stresses) acting on the formation at the wellbore well and they orthogonal to one another. The prediction of formation pore pressure profile is very vital. If it is wrongly predicted, it may be very difficult to establish a reasonable fit for wellbore stability analysis.

The presence of abnormally high in-situ stresses in salt domes, near faults, or inner limbs of folds usually leads to wellbore instability. Stress concentrations can also be found in stiff rocks i.e. sandstones or conglomerates. The major difficulty in analyzing this mechanism is estimating the in-situ stresses. The existing of naturally over-pressured shales as a result of geological phenomena i.e. 
under-compaction and uplift can lead to wellbore instability. These formations can collapse if the drilled open-hole section is filled with drilling fluid having insufficient mud weight. The best practices to stabilize these formations are ensuring short time open-hole exposure and sufficient mud weight while drilling through the formations.

\subsubsection{Gas Hydrate-Related Problems}

Gas hydrates are ice-like crystalline compounds formed when water molecules and light gas molecules exist together at high pressure and low temperature condition. Some of the gas hydrate formers are methane, ethane, propane, n-butane, i-butane, hydrogen sulfide, nitrogen, and carbon dioxide [2]. Most deepwater gas wells encounter hydrate problems because the temperature and pressure conditions of the environment are suitable for hydrate formation. The water molecules required for hydrate formation usually come from the drilling fluid or formation water produced with gas influx [2] [20]. In deepwater gas wells, risers are usually insulated while the BOP stake, choke and killlines are exposed to the surrounding. If gas kick occurs, the gas can form hydrates and block the BOP stack, choke and kill line. The formation of hydrates during drilling of deepwater gas wells can create series of undesirable effects such as plugging of choke and kill lines which prevents their use in well circulation; plugging of formation at or below the BOP's, which prevents wellbore pressure monitoring below the BOP's; plugging of formation around the drill string in the riser, BOP's, or casing, which prevents drill string movement; plugging of formation between the drill string and the BOP's, which prevents full BOP closure; and plugging of formation in the ram cavity of a closed BOP, which prevents the BOP from fully opening.

\subsubsection{Fractures, Faults and Mobile Reservoir Layers}

Wellbore instability problems have also been reported in naturally fractured formations having macro and micro scale bedding planes. The networks of natural fractures weaken the compressive strength of the formation and the producibility of the matrices in the formation [15] [21]. This changes the wellbore stress and reduce the fracture resistance of the formation. Reservoir layers that are close to fault zones can be disintegrated into different segments which can be trapped in the wellbore and lead to jamming of the drill string. This problem is common in tectonically active zones and fractured limestone [21]. Such fractures in shale formations can create pathway for drilling fluid invasion, reduce the strength of the formation and can cause wellbore collapse. Mobile layers in the reservoir can easily squeeze into the wellbore when compressed due to overburden stress. Mobile layers behave like plastic materials and deform under excessive pressure. This deformation can reduce the wellbore size and affects downhole tools such as BHA's, logging tools and even the casing strings, as shown in Figure 1. This occurs mostly when drilling through salt formations. Drilling fluid with sufficient mud weight can be used to stabilize these formations. 


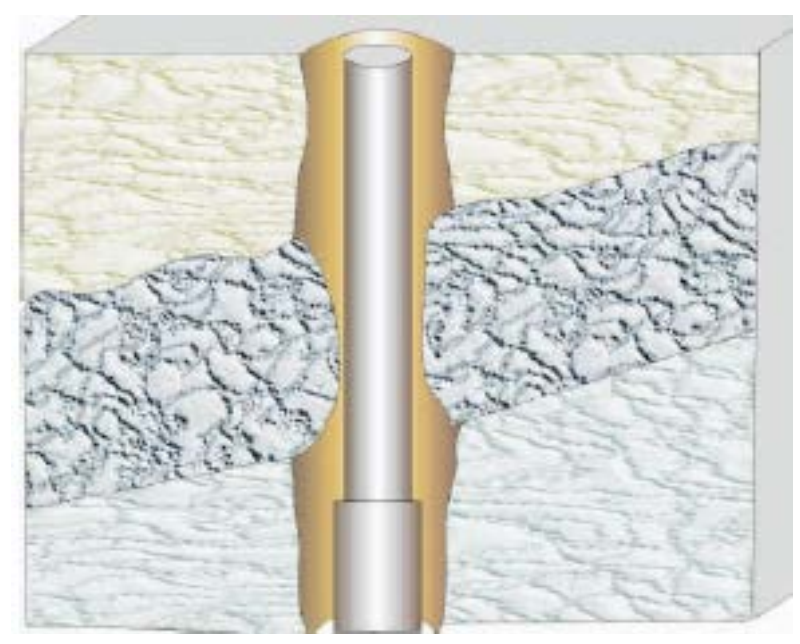

Figure 1. Drilling through mobile reservoir layers [21].

\subsubsection{Tectonically Stressed/Unconsolidated Formations}

When rock layers are compressed or stretched due to earth's movement, tectonic stresses are created. The compressed or stretched rock strata are buckled by the overburden pressure of the moving tectonic plates. When drilling through tectonically stressed formations, the layers around the wellbore can collapse and lead to wellbore instability. In these rock strata, mud hydrostatic pressure required to stabilize the wellbore section may be greater than the formation fracture pressure [21] [22]. This phenomenon is common inmountainous regions. The best practices to stabilize these formations are running casing strings as quickly as possible and ensuring that the wellbore is filled with sufficient drilling fluid at all times.

Unconsolidated formations are loosely packed with little or no bonding among the particles or pebbles and can easily fall into the open-hole section while drilling. If the drill string is removed or casing strings are not immediately run, the formation can collapse, as shown in Figure 2. If there is insufficient mud cake and overbalance mud hydrostatic pressure, loss circulation will occur. Loose particles such as sand can fall into the open-hole section and pack off the down hole tools. This will lead to increase in drag and torque, and ultimately wellbore instability [21]. This phenomenon is common in shallow formation. The best practice to stabilize these formations is ensure adequate mud cake is created by filling the open-hole sections with sufficient drilling fluid at all times.

\section{Analysis of Wellbore Stability}

Wellbore stability analysis is usually conducted to validate and verify calculated stress and rock properties prior to drilling operations in deepwater exploration. Formation rock failure is an important phenomenon for oil and gas related rock mechanics because it is the origin of severe drilling problems such as wellbore instability. The analysis of rock mechanical properties and the in-situ stresses of the subsurface formations is therefore paramount for a successful drilling operation in deepwater gas reservoirs [22]. The basic knowledge of uniaxial compre- 


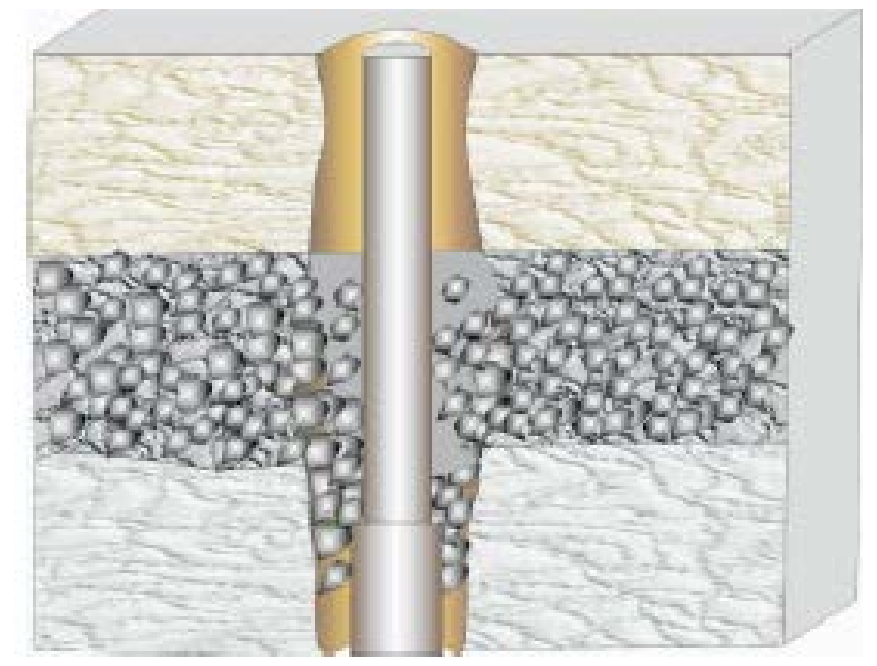

Figure 2. Drilling through unconsolidated formation [21].

ssive strength is vital in addressing geo-mechanical analysis ranging from wellbore stability, compaction, subsidence and constraining stress magnitudes. Accurate data on uniaxial compressive strength is usually determined through triaxial tests on cylindrical samples obtained from the target zones but there are limited core samples from deep water wellbores particular for shale formations [23].

Different empirical correlations have been developed to compute the compressive strength of hydrocarbon formation using readily available geophysical and petro physical properties i.e. porosity, density and elastic modulus, obtained from core laboratory measurements [22] [23]. However, these correlations are developed for specific rock type, stratigraphic and basin. The variation of rock compressive strength in a typical lithology depends on the mineral composition, pore geometry, grain size and contacts as well as the cement materials. Therefore, it is inappropriate to use one correlation for same rock type in different fields [23]. Prior to the drilling operation, the initial state of the rock compressive stress can be classified into three components which are vertical stress, minimum horizontal stress and maximum horizontal stress. The existing stress is redistributed immediately a well is drilled. The redistributed stresses are resolved into hoop stress acting circumferentially along the wellbore, radial stress and axial stress acting parallel to the axis of the wellbore [23] [24]. If the well is deviated, an additional component of shear stress is formed. The wellbore in the presence of drilling fluid pressure will remain stable if the rock compressive stress is sufficient to balance the redistributed stresses. Therefore, the computation of rock compressive strength is crucial for wellbore stability analysis.

Kumar and Rao, [23] used the workflow in Figure 3 for wellbore stability analysis of the deepwater gas formation and the following steps were used for the analysis:

1) Relevant data such as geologic/seismic data, well logs, leak-off tests and formation pore pressure profile were collected and analyzed. 




Figure 3. Workflow for wellbore stability analysis [23].

2) Different lithologies i.e. clay and grain particles were identified at different depth intervals for petrophysical properties. Empirical relationships were used to obtain the rock mechanical properties such as Poisson ratio, Young's modulus and uniaxial compressive strength and the results were validated with experimental data.

3) Overburden gradient/vertical stress was determined by integrating formation density log data from the surface with respect to depth. Extrapolation curve can also be used to calculate the vertical stress.

4) Formation pore pressure profile was determined in shaly intervals using log-based methods i.e. sonic compressional slowness and resistivity, and calibrated with well test data.

5) Breakouts representing the minimum horizontal stress azimuth and fast shear azimuth representing maximum horizontal stress azimuth were used to compute horizontal stress directions profile.

6) Minimum and maximum horizontal stresses were determined from a poroelastic model and calibrated using formation leak-off tests data. Relative values were compared with the stress regime in the vicinity of the formation.

Theoretically, rock compressive strength models can be used to determine the strength of the formation and this can be used to calculate the effective safe mud window. The results obtained for the mud weight window is shown in Figure 4. Generally, wellbore stability analysis is expected to generate safe operating limits of the annular pressure i.e. mud weight, so that the drilling fluid density will be sufficient to ensure wellbore stability and also prevent fluid losses [24] [25]. Strength to half its value depending on other rock parameters and well profile.

If all factors are the same for the wellbore stability analysis, the mud weight required to prevent shear failure in the wellbore will increase by approximately $10 \%-25 \%$ with a decrease in compressive.

\subsection{Overburden/Vertical Stress}

The vertical stress also known as the overburden stress can also be determined 

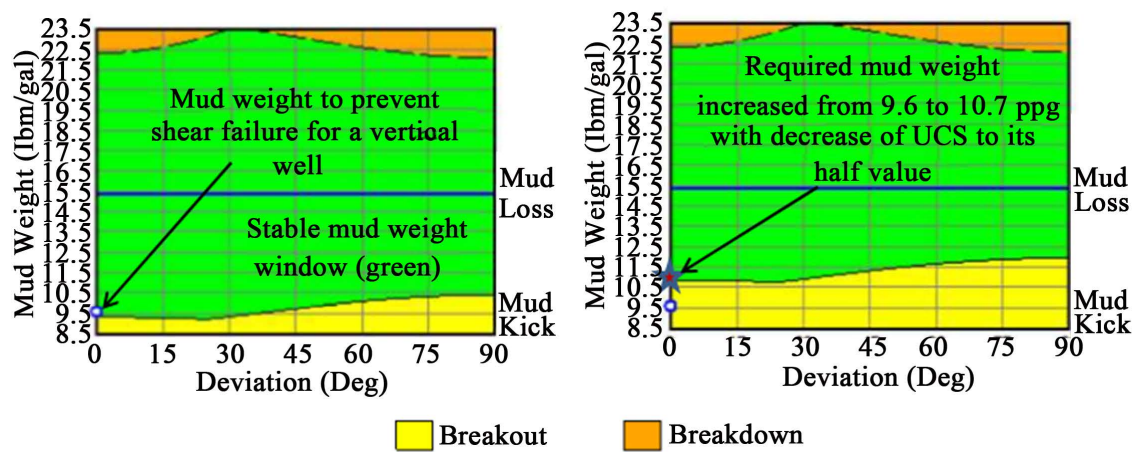

Figure 4. Sensitivity analysis for uniaxial compressive strength in a deepwater gas well [25].

using Equation (2) if the densities of the overlying formations are known [24] [25]. In the equation, $g$ is acceleration due to gravity; $\rho_{w}$ is the density of water, $z_{w}$ is water depth and $\rho_{b}$ is the density of the overlying formation at the depth $z$.

$$
\sigma_{V}=\rho_{w} g z_{w}+\int_{z_{w}}^{z} \rho_{b}(z) g \mathrm{~d} z
$$

\subsection{Minimum Horizontal Stress}

The minimum horizontal stress is an important parameter which can be used to determine the fracture gradient of any formation. Loss circulation of the drilling fluid into the formation usually occurs when the annular fluid pressure exceeds the minimum horizontal stress [26] [27]. This stress can be thought of as the pressure for extending an existing fracture in the wellbore wall. The plot of a typical leak-off is shown in Figure 5. This shows the relationships that exist among the leak-off pressure, formation breakdown pressure, fracture closure pressure and the minimum horizontal stress. This can be used to determine the minimum stress with a direct field observation.

The following Equations (3)-(5) can also be used to determine the minimum horizontal stress depending on the orientation of the formation under normal faulting stress regime but should be modified for other stress regimes.

$$
\sigma_{h}=\frac{v}{1-v}\left(\sigma_{V}-\propto p_{p}\right)+\propto p_{p}
$$

In Equation (3), $\sigma_{h}$ is the minimum horizontal stress; $p_{p}$ is the formation pore pressure; $\propto$ is the Biot's constant and $v$ is the Poisson's ratio. If there exist, horizontal strain and deformation effect, Hooke's law can be used to express the minimum horizontal stress and strain relationship as shown in Equation (4)

$$
\sigma_{h}=\propto p_{p}+\frac{v}{1-v}\left(\sigma_{V}-\propto p_{p}\right)+\frac{E * v}{1-v^{2}} \varepsilon_{H}+\frac{E}{1-v^{2}} \varepsilon_{h}
$$

Where $E$ is the Elastic modulus of the formation; $\varepsilon_{H}$ and $\varepsilon_{h}$ are the tectonic strains in the maximum and minimum directions respectively. For trans- 


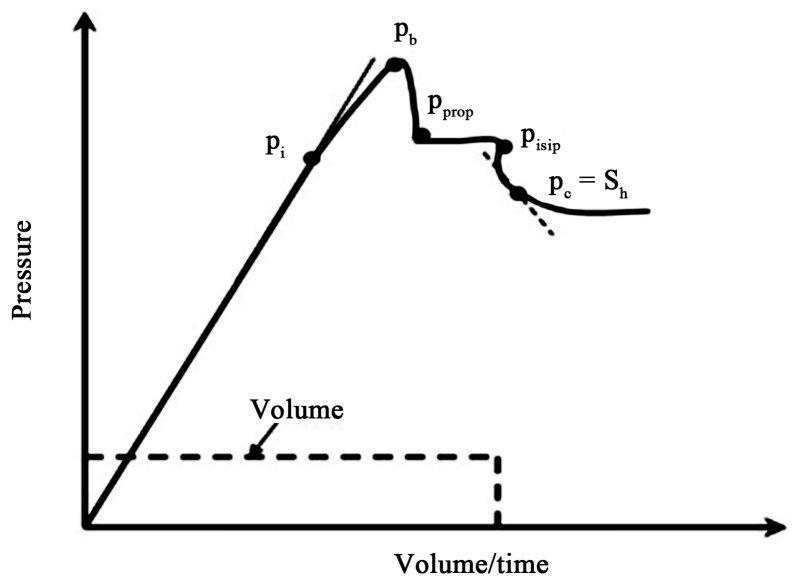

Figure 5. Decline curve of Leak-off tests [24].

versely anisotropic formations, Equation (5) can be used to determine the minimum horizontal stress.

$$
\sigma_{h}=\propto p_{p}+\frac{E_{h} v_{v}}{E_{H}\left(1-v_{h}\right)}\left(\sigma_{V}-\propto p_{p}\right)+\frac{E_{v} v_{v}}{1-v_{h}^{2}} \varepsilon_{H}+\frac{E_{h}}{1-v_{h}^{2}} \varepsilon_{h}
$$

In Equation (5), $E_{h}$ and $E_{v}$ are Young's modulus in the horizontal and vertical directions respectively, and $v_{h}$ and $v_{v}$ are the Poisson's ratios in the horizontal and vertical directions respectively.

\subsection{Maximum Horizontal Stress}

The maximum horizontal stress can be determined by using Equation (6) if the minimum horizontal stress and vertical stress are known.

$$
\sigma_{H}^{\max }=\sigma_{h}+k\left(\sigma_{V}-\sigma_{h}\right)
$$

where $k$ is an empirical factor normally from $0-2$, when the horizontal stresses are isotropic, the value of $k$ approaches 0 but when $k=0.5$, the maximum horizontal stress is the mean of the minimum horizontal stress and the vertical stress. If the pore pressure of the formation is known, the upper bound of the maximum horizontal stress can be determined using Equation (7). This is based on the generalized Hooke's law combined with the equilibrium of stresses and pore pressure [24] [27].

$$
\sigma_{H}^{\max }=\frac{\left(\sigma_{h}-\propto p_{p}\right)}{v}-\sigma_{v}+2 \propto p_{p}
$$

\subsection{Wellbore Shear Failure Gradient}

For effective analysis of wellbore stability, the minimum mud weight also known as the shear failure gradient requires to prevent wellbore collapse and the maximum mud weight required to prevent wellbore fracturing must be determined [24] [28]. The maximum mud weight in any drilled hole section is the minimum fracture gradient required to prevent wellbore shear fracture and also loss circulation. The minimum mud weight also known as the shear fracture gradient can 
be determined analytically from Kirsch's elastic solution. In a vertical well, when there is no shear stress, the effective stress on the wellbore wall can be resolved as shown in Equations (8)-(10).

$$
\begin{gathered}
\sigma_{z}^{\prime}=\sigma_{v}-p_{p}-v\left[2\left(\sigma_{H}-\sigma_{h}\right) \cos 2 \theta\right] \\
\sigma_{\theta}^{\prime}=\sigma_{H}+\sigma_{h}-p_{p}-p_{\text {mud }}-2\left(\sigma_{H}-\sigma_{h}\right) \cos 2 \theta \\
\sigma_{r}^{\prime}=p_{\text {mud }}-p_{p}
\end{gathered}
$$

where $\sigma_{z}^{\prime}, \sigma_{\theta}^{\prime}$, and $\sigma_{r}^{\prime}$ are the axial, tangential and radial stresses respectively, in the wellbore; $p_{\text {mud }}$ is the drilling mud pressure; $p_{p}$ is the formation pore pressure; $\sigma_{v}, \sigma_{H}$, and $\sigma_{h}$ are the vertical, maximum and minimum horizontal stresses respectively; $\theta=0^{\circ}$ is the maximum far-field direction and $\theta=90^{\circ}$ is the minimum far-field direction. If the Mohr-Coulomb failure criterion is used for the analysis of shear failure, assuming that the effective tangential and radial stresses are the principal maximum and minimum stresses, Equations (11) and (12) can be derived.

$$
\begin{gathered}
\sigma_{\theta}^{\prime} \leq U C S+q \sigma_{r}^{\prime} \\
p_{\text {mud }}=\frac{\sigma_{H}+\sigma_{h}-2\left(\sigma_{H}-\sigma_{h}\right) \cos 2 \theta-U C S+(q-1) p_{p}}{q+1}
\end{gathered}
$$

The rock uniaxial compressive strength (UCS) and $q$ can be determined by using Equation (13).

$$
\left\{\begin{array}{l}
U C S=\frac{2 c * \cos \varnothing}{1-\sin \varnothing} \\
q=\frac{1+\sin \varnothing}{1-\sin \varnothing}
\end{array}\right.
$$

In Equation (13), " $\varnothing$ " is the angle of internal friction and " $c$ " is the cohesion of the formation, $=90^{\circ}$, Equation (12) can be simplified to derive the expression for minimum mud pressure required to maintain the entire wellbore wall, as illustrated in Equation (14).

$$
p_{\text {mud }}^{\min }=\frac{3 \sigma_{H}-\sigma_{h}-U C S+(q-1) p_{p}}{q+1}
$$

\subsection{Formation Pore Pressure Distribution}

During underbalanced drilling of deepwater gas wells, the stress concentration of the wellbore is different from that of the over balanced drilling. Therefore, the parameters for wellbore stability analysis for overbalanced drilling should be modified for under balanced drilling conditions. In a conventional overbalanced drilling, mud-cake will accumulate on the wellbore wall and prevent mud filtrate from further invading the formation [29] [30].

The pore pressure on the wellbore wall can be determined using Equation (15), depending on the mud-cake efficiency as shown in Figure 6. Where is the formation pore pressure, is the initial reservoir pressure and $\mathrm{h}$ is the mud cake 


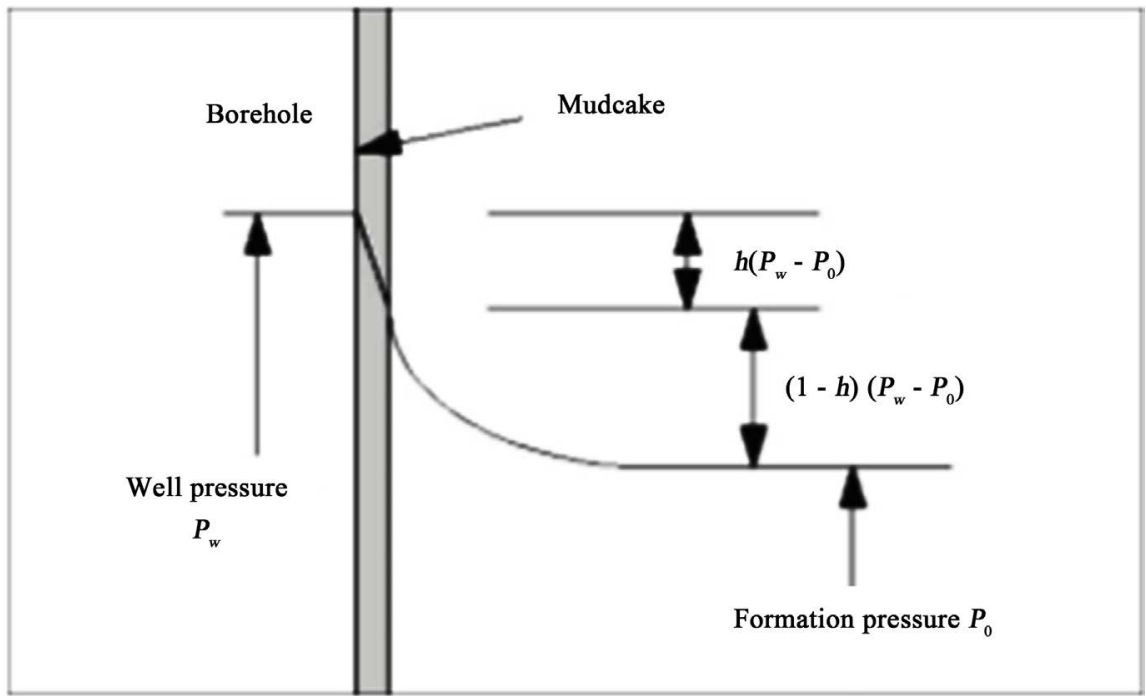

Figure 6. Drilling mud-cake hydraulic support [28].

coefficient between 0 (no mud cake) and 1 (perfect mud cake). The effective radial stress/support from the drilling mud is shown in Equation (16).

$$
\begin{gathered}
p_{p}=p_{0}+(1-h)\left(p_{w}-p_{0}\right) \\
\sigma_{r}^{\prime}=h\left(p_{w}-p_{0}\right)
\end{gathered}
$$

For underbalanced drilling, the distribution of formation pore pressure is different. During underbalanced drilling, the rock around the wellbore wall that should support the stress concentration at the wall is removed by drilling [28] [29]. In addition to change in in-situ stress distribution in the near wellbore region, there is also a change in pore pressure distribution. The initial pore pressure distribution is not in equilibrium with itself and the boundary conditions are altered. This gives rise to a transient flow regime in which the excessive pore pressure is gradually dissipated. For an underbalanced drilling of a highly permeable formation, the time taken for the initial transient pressure distribution to dissipate into steady state pressure regime is very short, usually in seconds, depending on the mobility of the fluid [30]. Therefore, it is expected that the wellbore stability for underbalanced drilling is governed by steady state flow regime rather than transient state flow regime.

For a homogeneous formation layer, Darcy's law can be used to estimate the pore pressure distribution as shown in Equation (17). Where $p_{e}$ is the formation pressure at the external boundary of the reservoir, $r_{e}$ and $r_{w}$ are the radii of the external and wellbore wall respectively from the axis of the wellbore, and the value of $r$ depends on the wellbore radius. The value of $r$ can be determined from Figure 7. If $p_{p} \approx p_{w}$ in the near wellbore region, $r<4 * r_{w}$.

$$
p_{p}-p_{w}=\frac{p_{e}-p_{w}}{\ln \frac{r_{e}}{r_{w}}}\left(\ln \frac{r}{r_{w}}\right)
$$




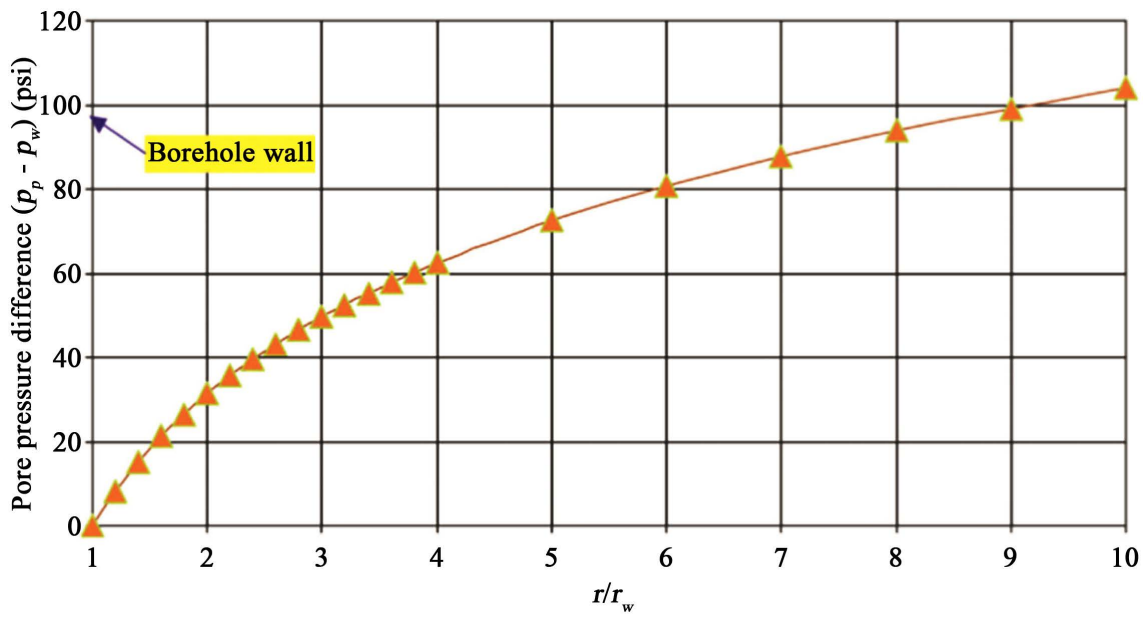

Figure 7. Formation pore pressure distribution during underbalanced drilling [28].

\section{Preventive Measures for Wellbore Stability Problems}

The analysis of wellbore stability is crucial in identifying the appropriate remedy orpreventive measure to mitigate the problem. The stability conditions depend on the establishment of sufficient hoop stresses capable of balancing the external load on the formation, otherwise, the rock particles may fail while drilling [31]. In some competent formations such as carbonate reservoirs, there might be a balance between the rock compressive strength and the stresses at the wellbore that ensures the rock integrity. Although some level of radial stresses may occur due to Biot-Willis coefficients, it might be insufficient to balance the concentrated stresses at the wellbore wall. This unbalanced stress can cause the formation to fail by shear stresses.

The instability problems in carbonate formations have been linked to mechanical loading that causes shearing zones at the wellbore wall. Different models for proper rock testing and parameterization have been used to mitigate these problems [32] [33]. In order to mitigate these problems and wellbore failure, it is paramount to optimize well trajectory, drilling mud weight and casing designs. Traditional wellbore stability analysis considered the formation to be isotropic and assumed that the rock mechanical properties are independent of direction. This assumption is invalid for formations with layers or natural fractures because the presences of these geological features lead to anisotropic elastic and strength properties of the formation. This has a significant influence on wellbore stress concentration, failure behavior and wellbore stability. Excessive pressure variation in the wellbore can create instability and other drilling problems. Accurate prediction of pressure variation is vital for estimating the maximum tripping or reaming speeds to keep the pressure in the wellbore within specified limits of the safe operational window [34] [35].

For deepwater gas wells, there is the possible of gas hydrate formation, if no hydrate prevention is implemented, due to the low temperature and high-pressure conditions of the environment as well as the coexistence of gas and water inside the wellbore [36] [37] [38]. The presence of water is the main cause of gas hy- 
drate formation, the first step in solving this problem is to use a proper oil-based mud or synthetic based mud for drilling to reduce water production from the invaded mud filtrate. In addition, different types of gas hydrate inhibitors can be used [39] [40]. The use of Methanol in large quantity, as a thermodynamic hydrate inhibitor can adjust the phase boundary thermodynamically to lower temperature and/or higher pressure. But in small quantity, methanol shows both inhibition and promotion effect. Another type of inhibitor is Polyvinylcaprolactum, PVCap which is a water-soluble polymer capable of delaying the growth of gas hydrate crystals. It is a kinetic hydrate inhibitor (KHI) and low dosage hydrate inhibitors (LDHIs). These inhibitors have low viscosity, good contact efficiency and relatively easy to dispose at the well site. Other preventive measures include but not limited to the following [41] [42] [43];

1) Increasing mud weight to stabilize hydrates but avoiding formation fracture,

2) Accelerating drilling and running casing strings immediately hydrates are encountered,

3) Using cement slurry of high strength and low heat of hydration, and

4) Controlling the wellbore temperature by adjusting the circulation rate of drilling mud.

The use of drilling mud weight to balance the stress and pressure concentration around the wellbore is not sufficient for effective wellbore stability. The properties of the drilling mud also play a vital role in successful drilling operation [44] [45]. Water-based drilling fluid creates more problems than oil based drilling fluid because of rock-fluid interactions. In drilling fluid design, sufficient plugging materials are required in the drilling fluid to mitigate fracture movement, shale disintegration, wellbore enlargementor collapse. These occur as a result of drilling mud filtrate invasion into the natural fractures in the formation. Plugging materials such as asphaltic additives, Gilsonite and Soltex are suitable mixtures for achieving optimum plugging effects of micro fractures in the formation to prevent fluid loss [41] [46].

Real-time monitoring of the operation is vital for wellbore stability analysis. Any unusual occurrence such as pressure changes, surge or swab changes, the rate of penetration, etc., can provide an early warning for wellbore instability especially for deepwater extended-reach and directional wells [42] [43]. It is almost impossible and unrealistic to have total prevention of wellbore instability because the physical and chemical in-situ properties of the rock cannot be restored to its original state. However, the wellbore stability problem scan be mitigated by adhering to good operational practices are, but not limited to [44] [45] [46]:

1) Proper selection and maintenance of drilling mud weight,

2) Using appropriate hydraulics to control the equivalent circulating density,

3) Selection of proper well trajectory,

4) Using compatible drilling fluid in the wellbore with the formation being drilled, 
5) Minimizing the time spent in open-hole sections,

6) Using relevant offset well data,

7) Monitoring changes in different parameters such as torque, circulating pressure, drag, fill-in during tripping, etc., and

8) Mechanical earth models or flux calculations can be used to estimate when an open-hole section will collapse, fracture or breakdown.

\section{Conclusions}

Wellbore instability problems in deepwater exploration and production are expected when drilling through shale, unconsolidated sandstone and fractured carbonate formations as well as HPHT formations with narrow drilling safety margin. There is also the possibility of gas hydrate problems due to the low temperature and high-pressure conditions of the environment, and the presence of gas and water in the wellbore. These hydrates may result in gasification of the drilling mud and reduce drilling mud density, hydrostatic pressure, change mud rheology and wellbore instabilities i.e. wellbore enlargement or collapse.

The analysis of rock mechanical properties and the in-situ stresses of the subsurface formations is vital for a successful drilling operation in deepwater gas formations. This will provide comprehensive details of the macro and micro scale bedding planes and networks of natural fractures that can affect the formation properties and redistribute the in-situ stresses while drilling. The factors that affect wellbore stability must be known to ensure successful drilling operations. In this comprehensive review paper, the causes of wellbore stability problems are investigated and preventive measures are also outlined for effective deepwater drilling operations. Real-time monitoring of the whole process can provide necessary information for solving any wellbore instability problems in a short time.

\section{References}

[1] You, L., Kang, Y., Chen, Z., Chen, Q. and Yang, B. (2014) Wellboreinstability in Shale Gas Wells Drilled by Oil-Based Fluids. International Journal of Rock Mechanics \& Mining Sciences, 72, 294-299.

[2] Ghajari, M.P., Sabkdost, A. and Soghondikolaee, H.T. (2010) Hydrate-Related Drilling Hazards and Their Remedies. 2nd National Iranian Conference on Gas Hydrate, Semnan University, 1-12.

[3] Nicoline de Sa, A. and Soares, A.C. (1997) Coring Samples and Obtaining Geochemical Properties for Wellbore Stability Analysis in Deepwater Brazilian Horizontal Wells. SPE 39070, Paper Presentation at the 5th Latin American and Caribbean Petroleum Engineering Conference and Exhibition, 1-8. https://doi.org/10.2118/39070-MS

[4] Aregbe, A.G. (2017) Gas Hydrate-Properties, Formation and Benefits. Open Journal of Yangtze Gas and Oil, No. 2, 27-44.

[5] Asadi, M.S., Khaksar, A., White, A. and Yao, Z. (2015) Wellbore Stability Analysis in Depleted Deepwater Reservoirs: A Case Study from Australia. SPE-172685-MS, Paper Presentation at the SPE Middle East Oil \& Gas Show and Conference, Ba- 
hrain, 1-16.

[6] Klimentos, T. (2005) Optimizing Drilling Performance by Wellbore Stability and Pore Pressure Evaluation in Deepwater Exploration. Paper Presentation at the International Petroleum Technology Conference, Qatar, IPTC 10933, 1-7.

[7] Alkamil, E.H.K., Abbood, H.R., Flori, R.E. and Eckert, A. (2017) Wellbore Stability Evaluation for Mishrif Formation. Paper Presentation at the SPE Middle East Oil \& Gas Show and Conference, Bahrain, 1-15.

[8] Van Oort, E., Ripley, R.D., Chapman, J.W., Williamson, R. and Aston, M. (1996) Silicate-Based Drilling Fluids: Competent, Cost-Effective and Benign Solutions to Wellbore Stability Problems. Paper Presentation at the19961ADC/SPE Drilling Conference, Louisiana, 213-235.

[9] Anyanwu, C., Dosunmu, A., Fakete, P., Ekeinde, E. and Odagme, B. (2013) Analysis of Wellbore Stability in Multilateral Well Design and Construction. SPE 167546, Paper Presentation at the Nigeria Annual International Conference and Exhibition, Nigeria, 1-12.

[10] Willson, S.M., Edwards, S., Heppard, P.D., Li, X., Coltrin, G., Chester, D.K., Harrison, H.L., Cocales, B.W. and Bybee, K. (2003) Wellbore Stability Challenges in the Deep Water, Gulf of Mexico: Case History Examples from the Pompano Field. SPE 84266, Article for SPE Annual Technical Conference and Exhibition, Denver, 61-62.

[11] Fekete, P., Dosunmu, A., Anyanwu, C., Odagme, S.B. and Ekeinde, E. (2014) Wellbore Management in Weak Bedding Planes and Angle of Attack in Well Planning. SPE-172361-MS, Paper Presentation at the SPE Nigeria Annual International Conference and Exhibition, 1-13. https://doi.org/10.2118/172361-MS

[12] Van den Hoek, P.J., Kooijman, A.P., de Bree, P., Kenter, C.J., Zheng, Z. and Khodaverdian, M. (2000) Horizontal-Wellbore Stability and Sand Production in Weakly Consolidated Sandstones. SPE Drilling \& Completion, 15, 274-283. https://doi.org/10.2118/65755-PA

[13] Hoffers, B., Engeser, B. and Rischmiiller, H. (1994) Wellbore Stability of Asuper Deep Borehole in Crystalline Rock. SPE 28073, Paper Presentation at the Eurock SPE/ISRM Rock Mechanics, 371-378.

[14] Yang, H.J., Hao, L. and Wu, M.W. (2016) Risk Analysis of Gas Hydrate Formation during Deepwater Gas Well Testing. International Journal of Geo-Sciences, 7, 1057-1063.

[15] Fekete, P., Bruno, L.A., Dosumu, A., Odagme, S., Sanusi, A. and Bowe, E. (2015) The Effect of Wellbore Stability in Naturally Fractured Reservoirs. SPE-178267-MS, Paper Presentation at the Nigeria Annual International Conference and Exhibition, 1-15. https://doi.org/10.2118/178267-MS

[16] Shaughnessy, J.M., Armagost, W.K., Hermann, R.P. and Cleaver, M.A. (1999) Problems of Ultra-Deepwater Drilling. SPE/IADC 52782, Paper Presentation at the 1999 SPE/IADC Drilling Conference, Amsterdam, 1-10.

https://doi.org/10.2118/52782-MS

[17] Shaughnessy, J., Daugherty, W., Graff, R. and Durkee, T. (2007) More Ultra-Deepwater Drilling Problems. SPE/IADC 105792, Paper Presentation at the 2007SPE/IADC Drilling Conference, Amsterdam, 1-8. https://doi.org/10.2118/105792-MS

[18] Santos, H., Rego, L.F.B. and da Fontoura, S.A.B. (1997) Integrated Study of Shale Stability in Deepwater, Brazil. SPE 38961, Paper Presentation at the Fifth Latin American and Caribbean Petroleum Engineering Conference and Exhibition, Rio de Janeiro, 1-9. 
[19] Maury, V. (1994) Rock Failure Mechanisms Identification: A Key for Wellborestability and Reservoir Behavior Problem. SPE 28049, Paper Presentation at the 1994 Eurock SPE/ISRM Rock Mechanics in Petroleum Engineering Conference, Delft, 1-8. https://doi.org/10.2118/28049-MS

[20] Long, X., Tjok, K.M., Wright, C.S. and Witthoeft, A.F. (2014) Assessing Well Integrity using Numerical Simulation of Wellbore Stability during Production in Gas Hydrate Bearing Sediments. OTC-25155-MS, Paper Presentation at the Offshore Technology Conference, Houston, Texas, 1-14.

[21] Nmegbu, C.G.J. and Ohazuruike, L.V. (2014) Wellbore Instability in Oil Well Drilling: A Review. International Journal of Engineering Research and Development, 10, 11-20.

[22] Fekete, P.O., Dosunmu, A., Kuerunwa, A., Ekeinde, E.B., Anyanwu, C. and Odagme, B.S. (2013) Wellbore Stability Management in Depleted and Low-Pressure Reservoirs. SPE 167543, Paper Presentation at the Nigeria Annual International Conference and Exhibition, 1-18. https://doi.org/10.2118/167543-MS

[23] Kumar, R.R. and Rao, D.G. (2012) Review of Methods for Uniaxial Compressive Rock Strength Estimation in Deepwater Formation with Uncertainty Quantification in Wellbore Stability Analysis in absence of Core Measurements. SPE 150343, Paper Presentation at the SPE Deepwater Drilling and Completion Conference, Texas, $1-10$.

[24] Lang, J., Li, S. and Zhang, J. (2011) Wellbore Stability Modeling and Real-Time Surveillance for Deepwater Drilling to Weak Bedding Planes and Depleted Reservoirs. SPE/IADC 139708, Paper Presentation at the SPE/IADC Drilling Conference and Exhibition, 1-18.

[25] Khan, K., Halim, A., Hamid, A. and Al-Anazi, H.A. (2016) Optimum Mud Overbalance and ROP Limits for Managing Wellbore Stability in Horizontal Wells in a Carbonate Gas Reservoir. SPE/IADC-178217-MS, Paper Presentation at the SPE/IADC Middle East Drilling Technology Conference and Exhibition, UAE, 1-8.

[26] Li, S., George, J. and Purdy, C. (2012) Pore-Pressure and Wellbore-Stability Prediction to Increase Drilling Efficiency. SPE 144717, Technology Today Series Articles, 98-101.

[27] Omar, M., Rasli, F., Paimin, R., Maulana, H., Ghosh, A. and Abidin, Z.S. (2016) Overcoming Challenges in Pore Pressure Prediction and Wellbore Stability in Brunei Ultra Deepwater Exploration Well Campaign. SPE-182432-MS, Paper Presentation at the SPE Asia Pacific Oil \& Gas Conference and Exhibition, 1-21.

[28] Qiu, K., Gherryo, Y., Tan, C.P. and Marsden, R. (2008) Underbalanced Drilling of a Horizontal Well in Depleted Reservoir: A Wellbore-Stability Perspective. SPE 105215, Paper Presentation at the SPE Middle East Oil \& Gas Show and Conference, $1-9$.

[29] Ritter, D.G., Grollimund, B., Zoller, S.L. and Brecknock, D. (2003) Wellbore Stability in the Deepwater Bijupira \& Salema Fields, Offshore Brazil-A Probabilistic Approach. OTC 15205, Paper Presentation at the 2003 Offshore Technology Conference held in Houston, Texas, 1-13.

[30] Salehi, S., Hareland, G. and Dehkordi, K.K. (2007) Wellbore Stability Analysis in UBD Wells of Iranian Fields. SPE 105155, Paper Presentation at the 15th SPE Middle East Oil \& Gas Show and Conference, 1-8.

[31] Raggio Santos, E.S. and Ferriera, F.H. (2015) Wellbore Stability Model for Standalone Liner Completed Wells in Carbonate Reservoirs subjected to Acidizing Jobs-II. Wellbore Stability Simulators. OTC-26280-MS, Paper Presentation at the Offshore 
Technology Conference, Rio de Janeiro, 1-18.

[32] Shen, X., Bai, M. and Smith, R. (2010) Numerical Analysis on Subsalt Wellbore Stability in the Vioska-Knoll Deepwater of the Northern Region of the Gulf of Mexico. SPE 130635, Paper Presentation at the CPS/SPE International Oil \& Gas Conference and Exhibition, Beijing, 1-10.

[33] Udegbunam, J.E., Aadn, Y. and Fjelde, K.K. (2013) Uncertainty Evaluation of Wellbore Stability Model Predictions. SPE/IADC 166788, Paper Presentation at the SPE/IADC Middle East Drilling Technology Conference and Exhibition, Dubai, $1-15$.

[34] Yan, G., Karpfinger, F., Prioul, R., Tang, H., Jiang, Y. and Liu, C. (2014) Anisotropic Wellbore Stability Model and its Application for Drilling through Challenging Shale Gas Wells. IPTC-18143-MS, Paper Presentation at the International Petroleum Technology Conference, Malaysia, 1-14. https://doi.org/10.2523/IPTC-18143-MS

[35] Zhang, F., Kang, Y., Wang, Z., Miska, S., Yu, M. and Zamanipour, Z. (2016) Real-Time Wellbore Stability Evaluation for Deepwater Drilling during Tripping. SPE-180307-MS, Paper Presentation at the SPE Deepwater Drilling \& Completions Conference, Texas, 1-19.

[36] Chen, S., Gong, W.X. and Antle, G. (2008) DST Design for Deepwater Wellswith Potential Gas Hydrate Problems. OTC 19162, Paper Presentation at the 2008 Offshore Technology Conference, Texas, 1-9.

[37] Aregbe, A.G. (2017) Natural Gas Flaring-Alternative Solutions. World Journal of Engineering and Technology, No. 5, 139-153.

[38] Khabibullin, T., Falcone, G. and Teodorlu, C. (2011) Drilling through Gas-Hydrate Sediments: Managing Wellbore-Stability Risks. SPE 131332, Paper Presentation at the EUROPEC/EAGE Conference and Exhibition, 287-294. https://doi.org/10.2118/131332-PA

[39] Salehabadi, M., Jin, M., Yang, J., Ahmed, R. and Tohidi, B. (2010) The Effect of Casing Eccentricity on the Casing Stability Analysis of a Wellbore drilled in a Gas Hydrate Bearing Sediment. SPE 131236, Paper Presentation at the SPEEUROPEC/EAGE Annual Conference and Exhibition, Barcelona, 1-15. https://doi.org/10.2118/131236-MS

[40] Satterlee, K., Smith, D.L., Barringer, J.J., Blythe, B.J., Brzuzy, L.P., Campbell, C.E., Cooper, J.E., Danenberger, E.P., Else, M., Freeman, A., Gooding, J.L., et al. (2011) Subsea Drilling, Well Operations and Completions. NPC North American Resource Development Study, 1-45.

[41] Lea, J.F. and Nickens, H.V. (2004) Solving Gas-Well Liquid-Loading Problems. SPE 72092, Distinguished Author Series Articles, 30-36.

[42] Meng, F. and Fuh, G. (2013) Wellbore Stability Evaluation Guideline for Reducing Non-Productive Time. IPTC 16567, Paper Presentation at the International Petroleum Technology Conference, Beijing, 1-10. https://doi.org/10.2523/IPTC-16567-MS

[43] Cuvillier, G., Edwards, S., Johnson, G., Plumb, D., Sayers, C., Denyer, G., Mendonca, J.E., Theuveny, B. and Vise, C. (2000) Solving Deepwater Well-Construction Problems. Oilfield Review, 1-7.

[44] Greenwood, J.A., Brehm, A., van Oort, E., Algu, D.R. and Volokitin, Y.E. (2005) Application of Real-Time Wellbore Stability Monitoring on a Deepwater ERD Well. SPE/IADC 92588, Paper Presentation at the SPE/IADC Drilling Conference, Amsterdam, 1-14. https://doi.org/10.2118/92588-MS

[45] Tare, U.A., Mody, F.K. and Tan, C.P. (2002) Mitigating Wellbore Stability Problems 
while Drilling with Water-Based Muds in Deepwater Environments. OTC 14267, Paper Presentation at the Offshore Technology Conference, Texas, 1-8.

[46] Wilson, S.M. (2012) A Wellbore Stability Approach for Self-Killing Blowout Assessment. SPE 156330, Paper Presentation at the SPE Drilling and Completion Conference, Texas, 1-16. https://doi.org/10.2118/156330-MS 